\title{
Serous Cysts Are a Benign Component of the Cyclic Ovary in the Guinea Pig with an Incidence Dependent upon Inhibin Bioactivity
}

\author{
FangXiong SHI ${ }^{1,2,3)}$, Brian K. PETROFF ${ }^{4)}$, Chandana B. HERATH ${ }^{2)}$, Manao OZAWA ${ }^{2)}$, Gen WATANABE ${ }^{1,2)}$ and \\ Kazuyoshi TAYA ${ }^{1,2) *}$ \\ 1)Department of Basic Veterinary Sciences, The United Graduate School of Veterinary Sciences, Gifu University, Gifu 501-1109, \\ ${ }^{2)}$ Laboratory of Veterinary Physiology, Tokyo University of Agriculture and Technology, Tokyo 183-8509, Japan, ${ }^{3)}$ College of Animal \\ Sciences, Zhejiang University, Hangzhou 310029, China and ${ }^{4)}$ Department of Molecular and Integrative Physiology, University of Kansas \\ Medical Center, Kansas City, KS 66160, U.S.A.
}

(Received 9 May 2001/Accepted 7 November 2001)

ABSTRACT. Ovaries were collected from normal cycling female guinea pigs on each day of the estrous cycle ( $\mathrm{n}=5$ per day) for histological analysis of ovarian morphology. Three types of ovarian cysts were observed: serous cysts, follicular cysts and parovarian cysts. The most common were serous cysts (cystic rete ovarii), which were present throughout the estrous cycle with an overall incidence of $63.5 \%$ (54 out of 85 animals). Follicular cysts occurred in $22.4 \%$ of guinea pigs overall (19 out of 85 ). Only one parovarian cyst ( 1 out of 85) was observed in the present experiment. Follicular cysts always coincided with serous cysts and were less common during diestrus. The incidence of serous cysts did not vary significantly across the estrous cycle. In a second experiment, cycling female guinea pigs were arrested in a prolonged luteal phase by a progesterone implant in order to achieve ovarian synchrony. They were then treated with inhibin antiserum ( 0.5 or $1 \mathrm{~m} l$ per animal i.v.; $\mathrm{n}=6$ per group) or normal goat serum (controls; $\mathrm{n}=6$ per group). There was a dose dependent increase in the incidence of serous ovarian cysts following passive immunization against the inhibin $\alpha$-subunit. These results suggest that serous cysts are a normal component of the cyclic guinea pig ovary and that alterations in the inhibin-follicle-stimulating hormone system appear to modulate the incidence of serous ovarian cysts in this species.

KEY WORDS: guinea pig, inhibin, ovarian cyst, passive immunization, serous cyst.

J. Vet. Med. Sci. 64(2): 129-135, 2002

Infertility associated with ovarian cysts is common in a variety of species, including humans and guinea pigs [12, $25,35,36,48]$. Investigation of cystic or polycystic ovarian disease is complicated because of the benign nature of the occurrence of these cysts in the ovary of females in many species $[18,49]$. In the present study, we examined the incidence of ovarian cysts in otherwise healthy female guinea pigs of reproductive age and investigated the potential role of inhibins in the pathophysiology of cystic ovarian disease in this species.

We chose the guinea pig as our experimental model because of the similarities of the reproductive cycle between the human and guinea pig, and the ready availability of relevant hormonal data for this species. However, little information is available about the incidence of ovarian cysts in the guinea pig, particularly in young females [14]. The histological characteristics of ovarian cysts during the estrous cycle of the guinea pig remain unknown as well.

Inhibins are glycoprotein hormones of gonadal origin, composed of two dissimilar disulfide-linked subunits ( $\alpha$ and $\beta$ ). They are developmentally and physiologically important growth factors with structural homology to a large group of proteins including the transforming growth factor$\beta$ (TGF- $\beta$ ) [51], and have been reported to play a role in cystic ovarian diseases $[4,5,19]$. Similar to other members of the TGF- $\beta$ family, inhibins interact with cell surface recep-

\footnotetext{
* Correspondence to: Taya, K., Laboratory of Veterinary Physiology, Tokyo University of Agriculture and Technology, 3-5-8 Saiwai-cho, Fuchu, Tokyo 183-8509, Japan.
}

tors [29]. Inhibin suppresses secretion of gonadotropins from the anterior pituitary gland, and preferentially inhibits follicle-stimulating hormone (FSH) secretion through suppression of FSH $\beta$-subunit protein synthesis [8]. In addition, inhibin decreases the number of gonadotropin releasing hormone $(\mathrm{GnRH})$ cell surface receptors on the gonadotrophs [9]. In the ovary, granulosa cell-derived inhibin can enhance LH-stimulated androgen secretion from thecal cells [20]. Matzuk et al. [30] found that transgenic mice lacking the inhibin $\alpha$-subunit developed granulosa cell tumors within a few weeks after birth. This observation led to the suggestion that the inhibin $\alpha$-subunit is a tumor suppressive factor in mice [30]. Immunoneutralization of inhibin consistently induced multiple ovulation in many mammals [15, 42, 44], and has been shown to be a more effective method of inducing superovulation in some species than the method using FSH and equine chorionic gonadotropin (eCG) treatment $[10,33,42-44]$. Immunoneutralization of inhibin has been used to investigate ovarian endocrine responses, follicular development, and ovulation rate $[16,50]$. However, induction of ovarian cysts in response to immunoneutralization of endogenous inhibin has not been documented.

\section{MATERIALS AND METHODS}

Animals and sampling procedure: Adult nulliparous female guinea pigs of the Hartley strain (obtained from Saitama Experimental Animal Supply Co., Ltd., Saitama, 
Japan), weighing 300-900 g, were used at 3-6 months of age. They were housed in metal cages with 3 animals per cage in a room with controlled temperature $\left(23 \pm 1^{\circ} \mathrm{C}\right)$ and lighting (lights on 0500 to $1900 \mathrm{hr}$ ), and provided with commercial pellets (GB-1: Nihon Nousan Kougyou Co., Ltd., Kanagawa, Japan) and tap water ad libitum. Estrous cycle was monitored by daily examination of the vaginal membrane and smears were taken by lavage when the vagina was open. The day of ovulation was estimated as the day when maximal cornification was seen in the smear before the ovulatory influx of leukocytes, and was designated Day 0 of the cycle.

To investigate the prevalence of ovarian cysts during the estrous cycle, eighty-five guinea pigs ( 5 animals on each day of the cycle) were sacrificed and their ovaries were removed, weighed and immediately fixed in 4\% paraformaldehyde (PFA) for histological examination.

In order to determine whether neutralization of endogenous inhibin changes the incidence of ovarian cysts in guinea pigs, ovaries and plasma were collected following immunoneutralization of inhibin as described previously [45]. Briefly, each of 18 female guinea pigs received a subcutaneous implant (Silastic tubing, $1.0 \mathrm{~cm}$ long, $0.4 \mathrm{~cm}$ i.d.; Dow Corning Co., Midland, MI, U.S.A.) of crystalline progesterone for 3 to 4 weeks; this treatment produced plasma concentrations of progesterone $(7.9 \pm 0.9 \mathrm{ng} / \mathrm{ml}$; $\mathrm{n}=9$ ) similar to those found during the luteal phase and also those found when ovulation is prevented [45]. This treatment regime synchronized ovarian functions by sustaining the cycle with a prolonged luteal phase. The animals received 0.5 or $1.0 \mathrm{~m} l$ of inhibin antiserum i.v. $(n=6$ per treatment group). Control animals received $1.0 \mathrm{~m} l$ of normal goat serum (NGS). The ovaries were collected for histological examination after the animals were sacrificed by an overdose of ether anesthesia at $48 \mathrm{hr}$ post-immunization. Inhibin antiserum used in the immunoneutralization experiment was generated using methods described previously [1]. The antigen for inhibin antiserum was porcine [Tyr 30]inhibin $\alpha(1-30)$ conjugated to rabbit serum albumin, kindly provided by Dr. N. Ling (Neuroendocrine Biosciences Inc., San Diego, CA, U.S.A.). The titer of the antiserum was determined as described previously [1]. The antiserum used in the present experiment had a titer of 1:1,000,000 as defined by a final dilution of the antiserum required to bind $50 \%$ of added ${ }^{125} \mathrm{I}$-labeled bovine $32-\mathrm{kDa}$ inhibin. Control serum was obtained from a castrated goat immunized against bovine serum albumin. The Institutional Animal Care and Use Committee of the Tokyo University of Agriculture and Technology approved all procedures involving animals in this study.

Histology: Ovaries were immediately removed from animals at necropsy, weighed and fixed in $4.0 \%$ PFA at room temperature overnight. After transferring through a graded series of alcohol and xylene, the tissues were embedded in paraffin and sectioned at $10 \mu \mathrm{m}$ thickness. The cystic ovaries were sectioned through the cyst wall at the thickest part of the parenchyma in an attempt to identify functional ova- rian tissue. The ovarian sections were mounted onto slides and stained with haematoxylin and eosin (HE).

Criterion for cyst identification: Identification of cystic ovaries in the present experiment was based on the ovarian tissue morphology of other reports [25, 35-37]. Follicular cysts were defined as large $(>500 \mu \mathrm{m}$ in diameter) cysts with a thin wall made up of one or several layers of granulosa cells, with a thickened, vacuolated theca layer in disarray, and full of fluid. Follicular cysts generally have no ova, so they can be distinguished from atretic follicles. Parovarian cysts were defined as vesicular structures located in the mesosalpinx or mesovarium. Serous cysts (also called cystic rete ovarii $[14,25])$, were identified by their simple ciliated low cuboidal to columnar epithelium. Serous cysts having a diameter of more than $500 \mu \mathrm{m}$ were evaluated by histological examination (this excluded small vascular tissue and small empty spaces of the ovary).

Statistics: All data were expressed as mean \pm standard errors $( \pm$ SEM). Differences in ovarian weights and the prevalence of ovarian cysts between groups were analyzed using one-way ANOVA followed by Duncan's multiple range test or student's $t$ test. A p value $<0.05$ was considered significant.

\section{RESULTS}

Incidence of ovarian cysts during the normal estrous cycle of the guinea pig: All three types of ovarian cysts (follicular, parovarian and serous) were found in the ovary of the guinea pig based on ovarian morphology and histology (Fig. 1). Serous ovarian cysts were most common (Fig. $1 \mathrm{~A}$ to $\mathrm{H}$ ) and were observed on every day of the estrous cycle (Fig. 2). The prevalence of serous cysts overall was $63.5 \%$ (54 out of 85 animals). Ovaries with serous cysts were consistently heavier than those without serous cysts (Fig. 3). Most serous cysts could be distinguished by the naked eye (Fig. 1. A, B) and were most common in the hilar region. In this region, there was a complex of branched tubular structures without a clear demarcation of their lumens (Fig. 1. A, B, E). Microscopic examination at higher magnification revealed large numbers of serous cysts, which varied considerably in diameter. The cystic walls appeared to be composed of two similar cell types; one was ciliated epithelium showing cylindrically shaped cells (Fig. 1D), and the other was cohesive and atypical cells, apparently composed of several layers linked with microvessel structures (Fig. 1H). Red blood cells were observed among the cohesive and atypical cells in the membrane wall of serous cysts (Fig. $1 \mathrm{H})$. Invaginations of connective tissues were also seen within some serous cysts (Fig. 1A).

Follicular cysts were less prevalent than serous cysts (22.4\% incidence; 19 out of 85 animals) and the occurrence of these cysts in the ovary consistently coincided with the presence of serous cysts (Fig. 1 A, E, F). The incidence was greatest near the time of estrus (Fig. 2). Histologically, these follicle-derived cysts were relatively large with a thin wall made up of several layers of granulosa cells, and con- 

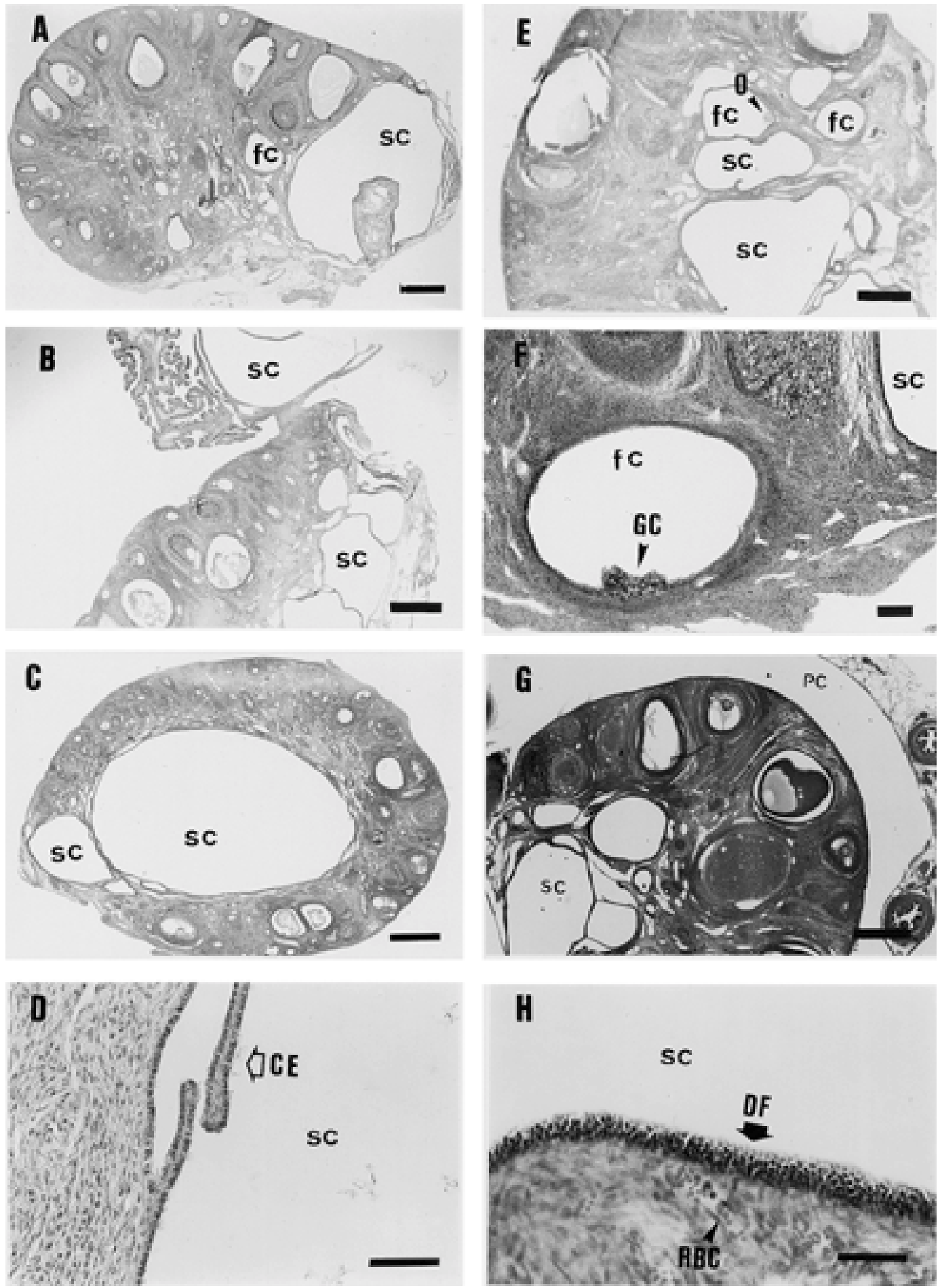

Fig. 1. Representative microphotographs of ovarian cysts in the guinea pigs. sc, serous cyst; fc, follicular cyst; pc, parovarian cyst; O, ova; GC, granulosa cells; $\mathrm{CE}$, ciliated epithelium; DF, differentiated cells; RBC, red blood cells. Bar: $\mathrm{A}, \mathrm{C}$ and $\mathrm{G}=500 \mu \mathrm{m} ; \mathrm{B}$ and $\mathrm{E}=250 \mu \mathrm{m} ; \mathrm{F}=100 \mu \mathrm{m} ; \mathrm{D}$ and $\mathrm{H}=50 \mu \mathrm{m}$.

tained an increased amount of fluid in the lumen (Fig. 1A, E, F). An oocyte was seen only in one follicular cyst (Fig. 1E).
Only one of the guinea pigs sacrificed on day 11 of the estrous cycle had a parovarian cyst in the ovary. 


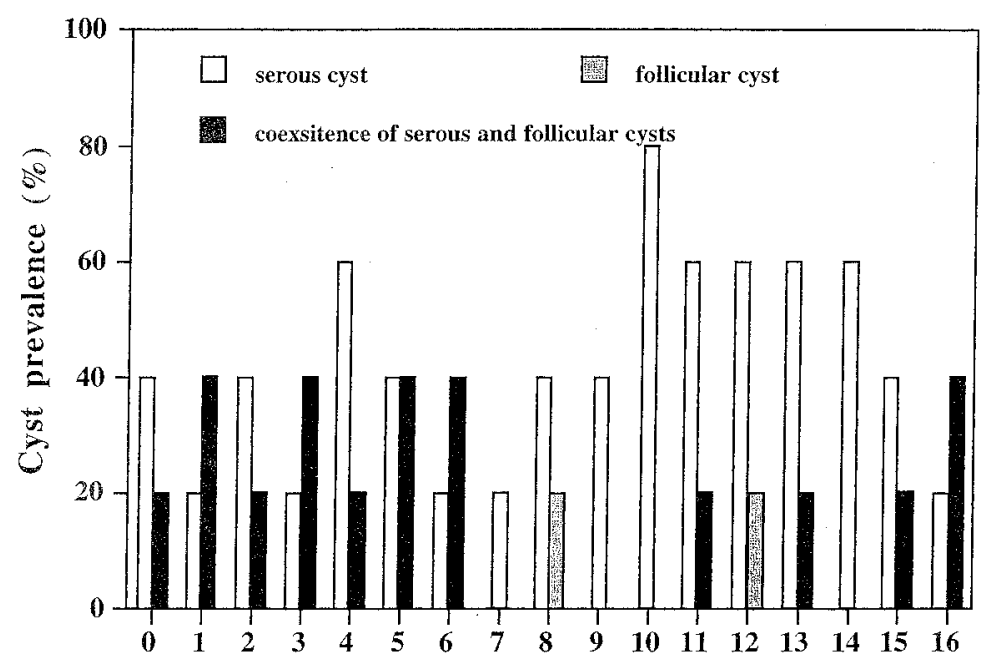

\section{Days of estrous cycle}

Fig. 2. Prevalence of ovarian cysts in guinea pigs during the estrous cycle. One ovary from each of five animals was used each day. Note the coexistence of serous and follicular cysts in the ovary during the estrous cycle.

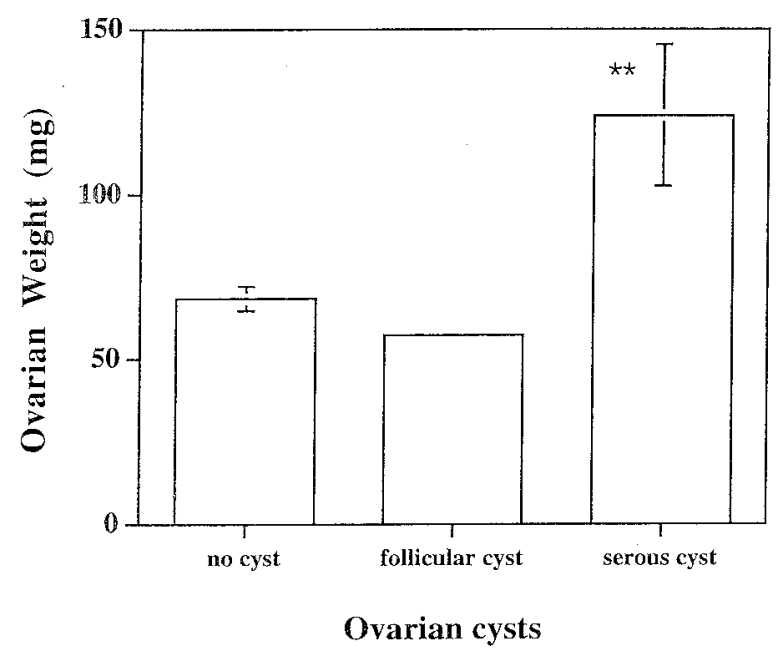

Fig. 3. The weights of ovaries with no cysts $(n=30)$, follicular cysts $(n=2)$ or serous cysts $(n=54$, including 16 ovaries coexisted with follicular cysts). $* * \mathrm{P}<0.01$ compared with the value of other groups (Duncan's multiple range test).

Effects of passive immunization against inhibin $\alpha$-subunit: Forty eight hours after injections of inhibin antiserum, ovarian weights had significantly $(\mathrm{P}<0.05)$ increased in a dose-dependent manner (Fig. 4A). Following the injection of inhibin antiserum, all of the animals developed serous cysts, whereas only about $67 \%$ of the animals injected with NGS had serous cysts in the ovary (Fig. 4B). Since there were no differences in the prevalence of serous cysts between the two immunized groups, the data from the two groups were pooled. Thus, the prevalence of serous cysts in the immunized groups was significantly $(\mathrm{P}<0.05)$ higher

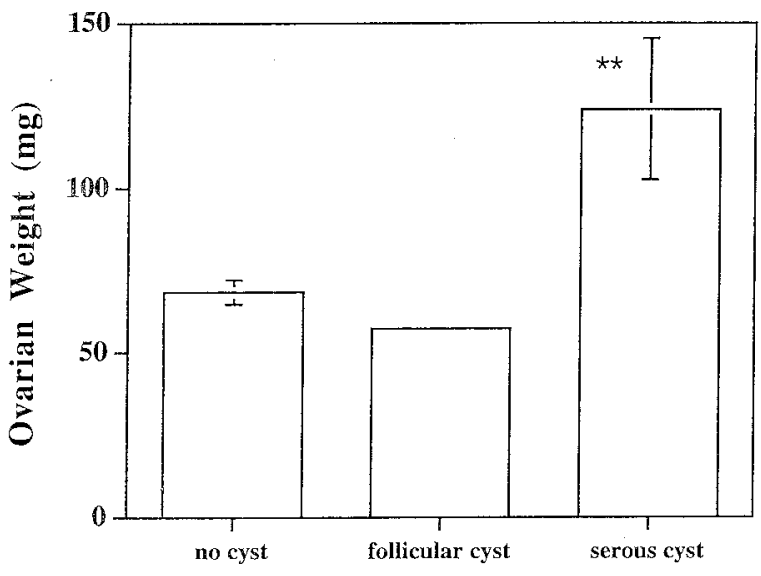

Ovarian cysts

Fig. 4. Effect of passive immunization against the inhibin $\alpha$-subunit on weight of ovaries (A) and prevalence of serous cysts (B). Values represent mean \pm SEM for 6 animals. ${ }^{*} \mathrm{P}<0.05$ $* * \mathrm{P}<0.01$ compared with the value of controls (Duncan's multiple range test).

than that in the non-immunized control group. There were no differences in the prevalence of follicular cysts between immunized groups and the control group $(16.7 \%, ; 2$ out of 12 vs. $16.7 \%$; 1 out of 6 , respectively).

\section{DISCUSSION}

The present results indicate that while both serous and follicular cysts occur commonly in healthy female guinea pigs of reproductive age, serous cysts occur throughout the 
reproductive cycle and are by far the most common cystic ovarian structure in this species. Only a single parovarian cyst was observed in the present study. The incidence of serous ovarian cysts and their prevalence in comparison with other types of ovarian cysts are in agreement with previous observations in older guinea pig $[14,25,36]$. The present results also show that passive immunization against the inhibin $\alpha$-subunit can increase the prevalence of serous cysts in guinea pigs. Taken together, these data suggest that defects in the inhibin-FSH system are sufficient to increase the incidence of serous ovarian cysts, the most common form of ovarian cysts in this species.

It is as yet unclear what roles, if any, inhibin has during the formation of ovarian cysts, especially in the human. Serum inhibin concentrations are elevated in most postmenopausal women with mucinous carcinomas of the ovary and some women with other types of epithelial ovarian tumors [19]. Concentrations of inhibin in serum fall after tumor removal [19]. It was reported that human ovarian cystic fluids produced a marked inhibition of FSH-binding activity in the absence of an effect on FSH or LH secretion [38]. Polycystic ovarian syndrome (PCOS) is the most common pathological cystic ovarian disease in human and is associated with a deficit in the paracrine control of folliculogenesis [4]. Autocrine/paracrine factors, especially those which are FSH-dependent, e.g. inhibin [51], probably play an important role in the pathogenesis of this ovarian abnormality [2]. The occurrence of hyperestrogenism together with hyperandrogenism in PCOS suggests that PCOS affects steroidogenesis in granulosa as well as theca cells [2].

Serous cysts, or in other words, cystic rete ovary [14, 25], are common $[11,34]$ in adult humans, and can also be observed occasionally in girls as well [7]. The lack of a suitable animal model has been an obstacle to the investigation of serous cysts in humans [31]. The guinea pig might be a good candidate for this purpose because of the morphological similarity between serous cysts in the human and guinea pig, characterized by a fluid-filled antrum surrounded by a dense epithelium or a highly vascularized basement membrane $[13,25,32,36]$. Furthermore, a higher natural incidence of cystic rete ovarii in the guinea pig [14, 25, 36] provides sufficient statistical power to dissect the effects of experimental treatments on the prevalence of this condition.

In previous studies, guinea pigs with serous ovarian cysts exhibited occasional clinical signs such as anorexia, alopecia, or lethargy [3], but no serious effects on fertility were observed [28], even in pregnant guinea pigs [40]. Wilkerson [49] stated that the rete ovarii is a normal structure in the adult ovary of humans, cows, sheep, pigs, dogs, cats, rabbits and rats. In the present study, the prevalence of serous cysts was a little lower than that in aged Abyssinian-Hartley crossed guinea pigs (76\%; 63 out of 83) [14] and Abyssinian guinea pigs ( $76 \% ; 54$ out of 71) [25], but higher than similar aged Hartley-albino guinea pigs [35]. This probably reflects strain-specific differences. Several researchers consider that serous cysts might be induced by contamination of feed with estrogen [40], but we saw no other evidence (e.g. uterine hypertrophy, aberrant vaginal cytology) of estrogenic contamination in our feed source.

Aberrant hormonal profiles have been suggested as a mechanism for ovarian cysts by several authors $[6,46,47$, 52]. In the present study, passive immunization against the inhibin $\alpha$-subunit increased ovarian weights in a dosedependent manner. This increase appeared to be associated with the formation of serous cysts. Passive immunization against inhibin increases plasma concentrations of FSH in many kinds of mammals, e.g. rats [1, 39], hamsters [26], cows [24], ewes [50] and mares [33]. The inhibin antiserum (TNDH-1) used in the present study displayed no significant cross-reaction with $\mathrm{LH}, \mathrm{FSH}$ and prolactin of rats, cattle and sheep, GnRH, transforming growth factor- $\beta$ or activin, whereas it cross-reacted with inhibin pro- $\alpha \mathrm{C}$ and free inhibin $\alpha$-subunit [23]. In vivo efficiency of the antiserum was ensured by an increase in plasma concentration of FSH in a dose dependent manner after an i.v. injection of the antiserum according to the method described previously [45]. Immunoneutralization of endogenous inhibin can increase plasma FSH probably through up regulation of pituitary FSH subunit mRNAs [8]. The increased FSH enhances the serous cyst formation, possibly by increasing the permeability of serous cysts resulting in fluid accumulation.

In a previous study in the rat, treatment with antiserum to inhibin resulted in a decrease in ovarian weights and fewer follicular cysts [22]. However, in the present study, passive immunization against inhibin did not alter the incidence of follicular cysts. This may be related to our use of progesterone implants to provide ovarian synchrony. Progesterone implants prevent follicular development [27, 41] and may have inhibited the occurrence of follicular cysts in the present study.

In conclusion, serous ovarian cysts are common throughout the estrous cycle of the guinea pig. Passive immunization against the inhibin $\alpha$-subunit in guinea pigs rapidly increased ovarian weights and the prevalence of serous cysts. Inhibin appears to modulate the incidence of serous ovarian cysts presumably through its regulation of FSH. Thus, the guinea pig may be a good model animal for the investigation of human serous ovarian cysts (cystic rete ovarii).

ACKNOWLEDGMENTS. We wish to express our gratitude to Dr. N. Ling, Neuroendocrine Inc., San Diego, CA, U.S.A. for providing [Tyr30]-inhibin $\alpha(1-30)$, and Teikoku Hormone, MFG Co. Ltd, Tokyo, Japan for providing progesterone. This work was supported in part by a grantin-aid (Monbusho International Scientific Research Program: Joint Research) from the Ministry of Education, Culture, Sports, Science and Technology of Japan, and USJapan Cooperative Research Grant from the Japan Society for Promotion of Science. 


\section{REFERENCES}

1. Arai, K., Watanabe, G., Taya, K. and Sasamoto, S. 1996. Roles of inhibin and estradiol in the regulation of follicle-stimulating hormone and luteinizing hormone secretion during the estrous cycle of the rat. Biol. Reprod. 55: 127-133.

2. Barnes, R.B. 1998. The pathogenesis of polycystic ovary syndrome: lessons from ovarian stimulation studies. J. Endocrinol. Invest. 21: $567-579$.

3. Beregi, A., Zorn, S. and Felkai, F. 1999. Ultrasonic diagnosis of ovarian cysts in ten guinea pigs. Vet. Radiol. Ultrasound. 40: 74-76.

4. Buckler, H.M., Robertson, W.R., Sun, J.G. and Morris, I.D. 1992. Immunoreactive inhibin levels during ovarian stimulation may predict granulosa cell maturity. Clin. Endocrinol. 37: 552-557.

5. Burger, H.G., Baillie, A.E., Drummond, A.E., Healy, D.L., Joblin, T., Mamers, P., Robertson, D.M., Susil, B., Cahir, N., Shen, Y., Verity, K., Fuller, P.J., Groome, N. P. and Findley, J.K. 1998. Inhibin and ovarian cancer. J. Reprod. Immunol. 39: 77-87.

6. Campion, C.E., Trewin, A.L. and Hutz, R.J. 1996. Effects of follicle-stimulating hormone administration on oestradiolinduced cystic ovaries in guinea pigs. Zoolog. Sci. 13: 137-42.

7. Canarelli, J.P., Plancq, M.C., Bob'Oyono, J.M. and Ricard, J. 1993. Voluminous ovarian cyst in children. Therapeutic strategy. J Chir (Paris). 130: 525-8.

8. Carroll, R.S., Corrigan, A.Z., Gharib, S.D., Vale, W. and Chin, W.W. 1989. Inhibin, activin, and follistatin: Regulation of follicle-stimulating hormone messenger ribonucleic acid levels. Mol. Endocrinol. 3: 1969-1976.

9. Culler, M.D. 1992. Inhibin suppresses luteinizing hormone (LH)-releasing hormone self priming: direct action on folliclestimulating hormone secretion and opposition of estradiol enhanced LH secretion. Endocrinology 130: 1605-1614.

10. D'Alessandro, A., Martemucci, G. and Iaffaldano, N. 1999. Active immunization with a synthetic fragment of pig inhibin $\alpha$-subunit increases ovulation rate and embryo production in superovulated ewes but season affects its efficiency. J. Reprod. Fertil. 115: 185-191.

11. Delaloye, J.F., Ruzicka, J. and De Grandi, P. 1993. An ovarian tumor of probable Wolffian origin. Acta Obstet. Gynecol. Scand. 72: 314-316.

12. Eden, J.A. and Warren, P. 1999. A review of 1019 consecutive cases of polycystic ovary syndrome demonstrated by ultrasound. Australas Radiol. 43: 41-6.

13. Eichhorn, J.H. and Scully, R.F. 1996. Endometrioid ciliatedcell tumors of the ovary: a report of five cases. Int. J. Gynecol. Pathol. 15: 248-56.

14. Field, K.J., Griffith, J.W. and Lang, C.M. 1989. Spontaneous reproductive tract leiomyomas in aged guinea-pigs. J. Comp. Pathol. 101: 287-294.

15. Findlay, J.K., Doughton, B. and Tsonis, C.G. 1993. Inhibin as fecundity vaccine. Anim. Reprod. Sci. 33: 325-343.

16. Glencross, R.G., Bleach, E.C., McLeod, B.J., Beard, A.J. and Knight, P.G. 1992. Effect of active immunization of heifers against inhibin on plasma FSH concentrations, ovarian follicular development and ovulation rate. J. Endocrinol. 134: 11-18.

17. Glueck, C.J., Awadalla, S.G., Phillips, H., Cameron, D., Wang, P. and Fontaine, R.N. 2000. Polycystic ovary syndrome, infertility, familial thrombophilia, familial hypofibrinolysis, recurrent loss of in vitro fertilized embryos, and miscarriage. Fertil Steril. 74: 394-7.
18. Halikias, I., Lytras, A., Syriou, V. and Tolis, G. 1997. Combined oral contraceptives and gonadotropin releasing hormone agonistic analogs in polycystic ovary syndrome: clinical and experimental studies. Eur. J. Contracept. Reprod. Health Care 2: $213-24$

19. Healy, D. L., Burger, H.G., Mamers, P., Joblin, T., Bangah, M., Quinn, M., Day, A.J., Rome, R. and Campbell, J.J. 1993. Elevated serum inhibin concentrations in postmenopausal women with ovarian tumors. New Engl. J. Med. 329: 15391542.

20. Hillier, S.G. 1991. Regulatory functions for inhibin and activin in human ovaries. J. Endocrinol. 131: 171-175.

21. Hunter, M.H. and Sterrett, J.J. 2000. Polycystic ovary syndrome: it's not just infertility. Am. Fam. Physician 62: 10791090.

22. Hurkadli, K.S., Jayaraman, S., Gopalakrishnan, K., Arbatti, N.J. and Sheth, A.R. 1986. Role of inhibin in polycystic ovarian syndrome. Int. J. Fertil. 31: 165-169.

23. Kaneko, H., Kishi, H., Watanabe, G., Taya, K., Sasamoto, S. and Hasegawa, Y. 1995. Changes in plasma concentrations of immunoreactive inhibin, estradiol and FSH during the follicular waves during the estrous cycle of cows. J. Reprod. Dev. 41: 311-320.

24. Kaneko, H., Nakanishi, Y., Taya, K., Kishi, H., Watanabe, G., Sasamoto, S. and Hasegawa, Y. 1993. Evidence that inhibin is an important factor in the regulation of FSH secretion during the mid-luteal phase in cows. J. Endocrinol. 136: 35-41.

25. Keller, L.S., Griffith, J.W. and Lang, C.M. 1987. Reproductive failure associated with cystic rete ovarii in guinea pigs. Vet. Pathol. 24: 335-339.

26. Kishi, H., Okada, T., Otsuka, M., Watanabe, G., Taya, K. and Sasamoto, S. 1996. Induction of superovulation by immunoneutralisation of endogenous inhibin through the secretion of FSH in cyclic golden hamster. J. Endocrinol. 151: 65-75.

27. Labhsetwar, A.P. and Diamond, M. 1970. Ovarian changes in the guinea pig during various reproductive stages and steroid treatments. Biol. Reprod. 2: 53-57.

28. Lipschutz, A. 1941. Spontaneous fibromyoma in a female guinea pig. Arch. Pathol. 31: 701-705.

29. Massague, J. 1992. Receptors for the TGF-beta family. Cell 69: 1067-1070.

30. Matzuk, M.M., Finegold, M.K., Su, J.G., Hsueh, A.J. and Bradley, A. 1992. Alpha-inhibin is a tumor suppressor gene with gonadal specificity in mice. Nature (Lond.) 360: 313-319.

31. Moulton, J.E. 1978. Tumors of the genital system. pp. 309345. In: Tumors in Domestic Animals, 2nd ed. (Moulton J.E. ed.), Univ. California Press, Berkeley.

32. Mulvany, N.J. 1996. Aspiration cytology of ovarian cysts and cystic neoplasms. A study of 235 aspirates. Acta Cytol. 40: 911-20.

33. Nambo, Y.T., Kaneko, H., Nagata, S., Oikawa, M., Yoshihara, T., Nagamine, N., Watanabe, G. and Taya, K. 1998. Effect of passive immunization against inhibin on FSH secretion, folliculogenesis and ovulation rate during the follicular phase of the estrous cycle in mares. Theriogenology 50: 545-557.

34. Parazzini, F., La Vecchia, C., Franceschi, S., Negri, E. and Cecchetti, G. 1989. Risk factors for endometrioid, mucinous and serous benign ovarian cysts. Int. J. Epidemiol. 18: 108-12.

35. Quandt, L.M. and Hutz, R.H. 1993. Induction by estradiol-17 $\beta$ of polycystic ovaries in the guinea pig. Biol. Reprod. 48: 10881094.

36. Quattropani, S.L. 1977. Serous cysts of the aging guinea pig ovary. I. Light microscopy and origin. Anat. Rec. 188: 351- 
360.

37. Quattropani, S.L. 1981. Serous cystadenoma formation in guinea pig ovaries. J. Submicrosc. Cytol. 13: 337-345.

38. Rettori, V., Van Sickle, M., Steinberger, A. and Asch, R.H. 1984. Follicle stimulating hormone binding inhibiting activity and inhibin properties of human ovarian cystic and porcine follicular fluid. Acta Eur. Fertil. 15: 93-97.

39. Rivier, C. and Vale, W. 1989. Immunization of endogenous inhibin modifies hormone secretion and ovulation in the rat. $J$. Endocrinol. 125: 152-157.

40. Schoenbaum, M. and Klopfer, U. 1969. Cystic changes in the ovaries of guinea pigs. Refuah. Vet. 26: 118-121.

41. Schneyer, A.L., Fujiwara, T., Fox, J., Welt, C.K., Adams, J., Messerlian, G.M. and Taylor, A.E. 2000. Dynamic changes in the intrafollicular inhibin/activin/follistatin axis during human follicular development: relationship to circulating hormone concentrations. J. Clin. Endocrinol. Metab. 85: 3319-3330.

42. Shi, F., Mochida, K., Ogura, A., Matsuda, J., Suzuki, O., Watanabe, G., Hutz, R.J., Tsonis, C.G., Suzuki, A.K. and Taya, K. 2000. Follicle selection in cyclic guinea pigs with active immunization against inhibin $\alpha$-subunit. Life Sci. 66: 24892497.

43. Shi, F., Mochida, K., Suzuki, O., Matsuda, J., Ogura, A., Tsonis, C.G., Watanabe, G., Suzuki, A.K. and Taya, K. 2000. Development of embryos in superovulated guinea pigs following active immunization against inhibin $\alpha$-subunit. Endocrine J. 47: 451-459.

44. Shi, F., Ozawa, M., Komura, H., Watanabe, G., Tsonis, C.G., Suzuki, A.K. and Taya, K. 2000. Induction of superovulation by inhibin vaccine in cyclic guinea pigs. J. Reprod. Fertil. 118: $1-7$.

45. Shi, F., Ozawa, M., Komura, H., Yang, P., Trewin, A.L., Hutz, R.J., Watanabe, G. and Taya, K. 1999. Secretion of ovarian inhibin and its physiologic roles in the regulation of folliclestimulating hormone secretion during the estrous cycle of the female guinea pig. Biol. Reprod. 60: 78-84.

46. Silva, E.G., Tornos, C., Fritssche, H.A. Jr., el-Naggar, A., Gray, K., Ordonez, N.G., Luna, M. and Gershenson, D. 1997. The induction of benign epithelial neoplasms of the ovaries of guinea pigs by testosterone stimulation: a potential animal model. Mod. Pathol. 10: 879-83.

47. Silva, E.G., Tornos, C., Deavers, M., Kaisman, K., Gray, K. and Gershenson, D. 1998. Induction of epithelial neoplasms in the ovaries of guinea pigs by estrogenic stimulation. Gynecol. Oncol. 71: 240-246.

48. Tweedy, A. 2000. Polycystic ovary syndrome. J. Am. Acad. Nurse Pract. 12: 101-105; quiz 106-108.

49. Wilkerson, W.V. 1923. The rete ovarii as a normal structure of the adult mammalian ovary. Anat. Rec. 26: 75-77.

50. Wheaton, J., Carson, K. and Kusina, N. 1992. Active and passive immunoneutralization of inhibin increases follicle stimulating hormone levels and ovulation rate in ewes. Biol. Reprod. 47: 361-367.

51. Woodruff, T.K. and Mather, J.P. 1995. Inhibin, activin and the female reproductive axis. Anim. Rev. Physiol. 57: 219-244.

52. Young, W.C., Dempsey E.W. and Myers H.I. 1936. The ovarian condition and sexual behavior in the female guinea pig. Am. J. Anat. 63: 457-487. 